\title{
Analisis Multi Kriteria Pos Hujan dan Pos Debit dengan Metode Stepwise pada DAS Bd. Katulampa
}

\author{
Ratih Pujiastuti \\ Undayani Cita Sari
}

\begin{abstract}
Abstrak:Dalam suatu WS/DAS, pos pencatatan curah hujan biasanya lebih banyak ditemui dibandingkan dengan pos pencatatan debit. Banyaknya jumlah pos hujan menimbulkan permasalahan dalam biaya operasi dan pemeliharaan. Penelitian ini bertujuan untuk menentukan pos hujan yang paling berpengaruh pada DAS Bd. Katulampa. Analisis dilakukan dengan metode Stepwise yang merupakan analisis multi correlation, dalam hal ini data hujan bulanan sebagai variabel bebas dan data debit bulanan sebagai variabel tidak bebas. DAS Bd. Katulampa dipengaruhi oleh 13 pos hujan. Akan tetapi karena keterbatasan data, analisis dilakukan pada 5 Pos Hujan yaitu Pos Perkeb. Gn. Mas, Pos Gunung Mas, Pos Panjang, Pos Pasir Muncang dan Pos Katulampa. Hasil analisa dengan multi correlation menunjukkan bahwa pertambahan nilai korelasi bertambah dari kombinasi 2,3 dan 4 pos hujan. Akan tetapi pada kombinasi 5 pos hujan, pertambahan nilai korelasi tidak lagi signifikan. Hal ini bisa disimpulkan bahwa pada DAS Bd. Katulampa, pencatatan pos hujan cukup terwakili dengan kombinasi 4 pos hujan antara lain Pos Perkeb. Gn. Mas, Pos Panjang, Pos Pasir Muncang dan Pos Katulampa. Kombinasi 4 pos hujan ini kemudian di cek dengan standar WMO. Polygon thiessen yang dihasilkan 4 pos hujan hasil analisis, menghasilkan luas pengaruh pos hujan maksimum adalah $50.57 \mathrm{~km} 2$ yaitu Pos Pasir Muncang dan minimum $15.46 \mathrm{~km} 2$ Pos Katulampa. Artinya dengan 4 pos hujan tersebut, luas pengaruh pos hujan masih masuk dalam ketentuan yang disyaratkan oleh WMO.
\end{abstract}

Kata-kata kunci: pos hujan, pos debit, multi correlation, stepwise

Abstract:In a WS / DAS, the rainfall recording post is usually more common than the debit recording post. The large number of rain stations has caused problems in operating and maintenance costs. This study aims to determine the most influential rainfall items in the watershed $B d$. Katulampa. The analysis was carried out using the Stepwise method which is a multi correlation analysis, in this case monthly rainfall data as the independent variable and monthly discharge data as the dependent variable. DAS Bd. Katulampa is affected by 13 rain posts. However, due to data limitations, the analysis was carried out on 5 Rain Posts, namely Perk Perkeb. Mt. Mas, Gunung Mas Post, Pos Panjang, Muncang Sand Post and Katulampa Post. The results of the analysis with multi correlation show that the correlation value increases from the combination of 2.3 and 4 rain posts. However, in the combination of 5 rain posts, the correlation value is no longer significant. It can be concluded that in the watershed Bd. Katulampa, the recording of rain posts is adequately represented by a combination of 4 rain posts, including the Pos Perkeb. Mt. Mas, Long Post, Muncang Sand Post and Katulampa Post. The combination of the 4 rain posts is then checked with the WMO standard. Polygon Thiessen produced by 4 analysis results, the maximum area of influence is $50.57 \mathrm{~km} 2$, that is Pasir Muncang Post and minimum $15.46 \mathrm{~km} 2$ Katulampa Post. This means that with the 4 rain posts, the broad influence of the rain post is still included in the conditions required by the WMO.

Keywords: rain post, debit post, multi correlation, stepwise.

\section{PENDAHULUAN}

Perencanaan infrastruktur keairan selalu diawali dengan perhitungan hidrologi. Data dasar hidrologi merupakan komponen penting yang diperlukan dalam analisis hidrologi. Data yang tidak akurat tentunya akan berpengaruh terhadap hasil akhir perencanaan.
Dalam perhitungan hidrologi, data dasar yang diperlukan adalah data debit atau tinggi muka air. Akan tetapi saat ini pos pencatatan data debit masih sangat terbatas. Hal ini bisa diatasi dengan mensimulasi data hujan menjadi data debit dengan model simulasi hujan-aliran (Hadisusanto, 1978).

Ratih Pujiastuti adalah Dosen Jurusan Sipil Fakultas Teknik Universitas Darul Ulum Islamic Centre Sudirman GUPPI Jalan Tentara Pelajar No. 13 Ungaran. 50514 Email: ratih.adiyanto@gmail.com; Undayani Cita Sari adalah Dosen Departemen Teknik Sipil Fakultas Teknik Universitas Diponegoro Email: undayanicita@live.undip.ac.id 
Pos pencatatan curah hujan biasanya lebih banyak ditemui dibandingkan dengan pos pencatatan debit. Banyaknya jumlah pos hujan menimbulkan permasalahan lain dalam pengelolaan data sumber daya air. Tidak jarang ditemui dalam satu lokasi terdapat 2 atau lebih pos hujan dengan kewenangan dari instansi yang berbeda. Hal ini tentunya berpengaruh terhadap biaya operasi dan pemeliharaan dari pos-pos tersebut.

Analisis multi correlation dengan Stepwise adalah salah satu metode untuk menentukan pos hujan yang paling berpengaruh dalam suatu DAS. Hal ini bertujuan untuk pengelolaan data yang lebih efektif dan efisien.

\section{METODE}

Rasionalisasi jaringan pos hidrologi adalah salah satu cara untuk mendapatkan jaringan hidrologi baru yang optimal dan efisien, sehingga dapat dikatakan bahwa data hidrologi yang diperoleh dari pospos ini dapat mewakili kondisi wilayah studi (Ayu, Shiami, \& Lasminto, 2019).

WMO (World Meteorological Organization) memberikan rekomendasi jumlah pos hujan yang optimal untuk berbagai wilayah. Untuk wilayah pegunungan satu alat penakar hujan mewakili wilayah seluas 100-250 $\mathrm{km} 2$. Sedangkan untuk perbukitan 575-5750 $\mathrm{km} 2$ dan perkotaan 10-20 km2 (WMO, 2008).

Dalam analisis rasionalisasi, ada banyak yang telah dikembangkan. Diantaranya metode Kagan (Rodda, 1972), Kriging (Junaidi, 2015), Kendali Mutu (G, Mirwan et al., 2019; Yuningsih \& G, 2017) dan Stepwise (Cipta et al, 2017; Kurniawati et al, n.d.) .
Ketepatan analisa hidrologi seharusnya didukung dengan adanya hubungan yang berkaitan antara data pos hujan dan pos duga air. Hal ini bisa dilakukan dengan menganalisa korelasi antara pos hujan dan pos duga air dengan metode Stepwise (Cipta et al., 2017).

Konsep dasar dari metode Stepwise ini adalah multiple correlation, oleh karena itu metode ini juga banyak disebut sebagai Metode Multi Korelasi. Umumnya metode Stepwise menggunakan data hujan bulanan sebagai variabel bebas dan data debit bulanan sebagai variabel tidak bebas dalam satu WS/ DAS/Sub DAS. Metode stepwise digunakan untuk merasionalisasi jaringan pos curah hujan. Kelebihan model ini adalah dapat memilih pos mana yang paling dominan dan mempunyai korelasi terbesar dengan pos pemantaudebit/posdugaair(KemenPUPR,2019).

Adapun urutan langkah dalam penelitian ini adalah:

1. Pengumpulan data,

2. Pembuatan peta DAS

3. Pembuatan poligon thiessen existing

4. Analisis single correlation

5. Analisis multi correlation

6. Pembuatan poligon thiessen hasil stepwise

\section{HASIL}

Penelitian ini dilakukan di DAS Bd. Katulampa dengan menggunakan data debit dari pos AWLR Bd. Katulampa dan pos hujan yang berpengaruh pada DAS tersebut. Untuk mengetahui pos hujan mana saja yang berpengaruh, dilakukan deliniasi peta daerah aliran sungai Bd. Katulampa. Peta DAS Bd. Katulampa dapat dilihat pada Gambar 1. 


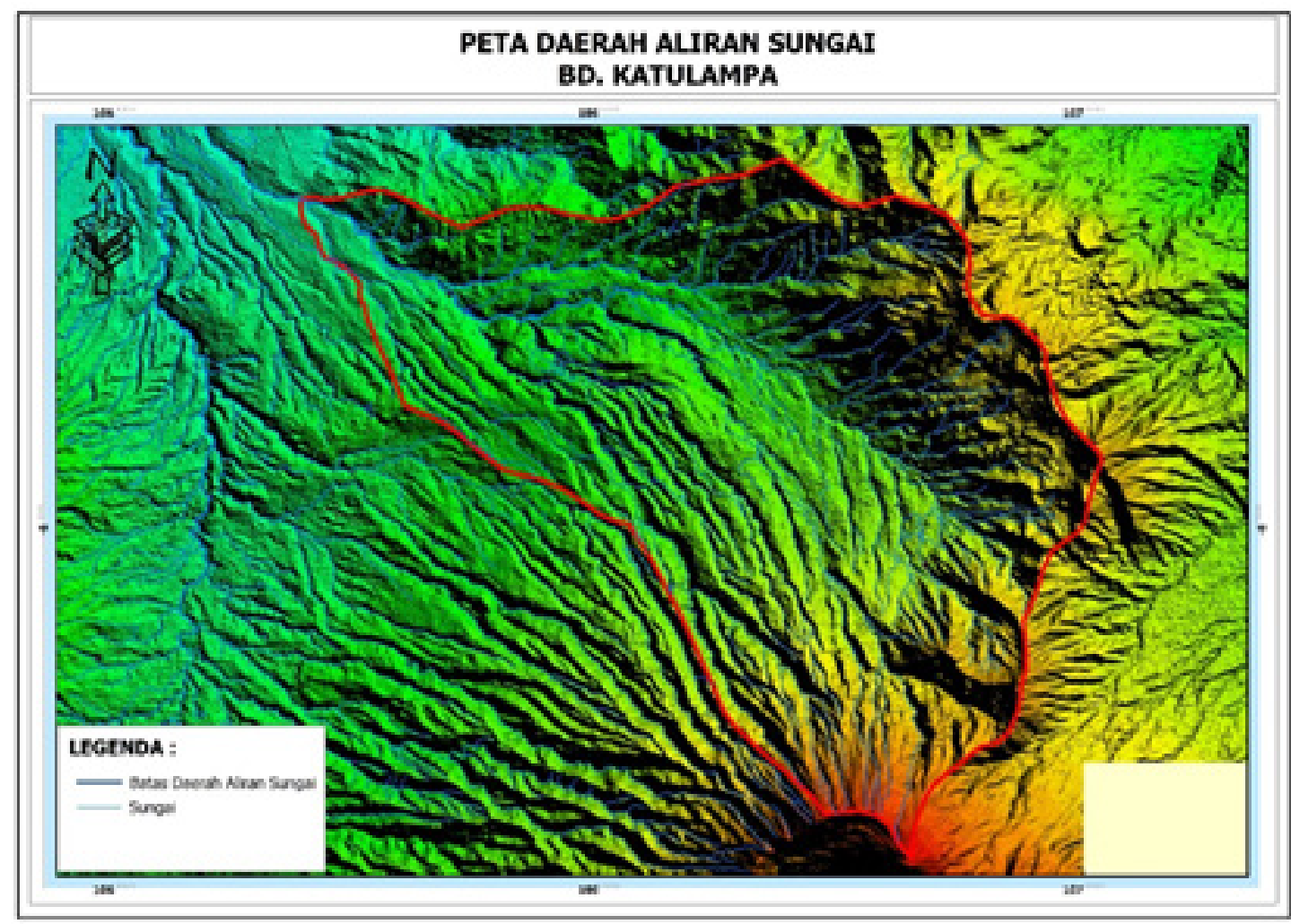

\section{Gambar 1. Peta Daerah Aliran Sungai (DAS) Katulampa}

Dari hasil deliniasi DAS, dilakukan plotting peta pos hujan yang ada di sekitar wilayah DAS tersebut. Setelah di plotting, dilakukan penggambaran polygon thiessen untuk pos hujan tersebut sehingga dapat dilihat pos hujan yang berpengaruh. Dari hasil plotting stasiun hujan pada DAS BD. Katulampa, diketahui bahwa pos ini dipengaruhi oleh 13 (tiga belas) pos hujan dari berbagai instansi. Adapun pos hujan yang berpengaruh ditabelkan dalam dan sebarannya dapat dilihat pada pada Gambar 2.

Tabel 1. Daftar Pos Hujan yang Berpengaruh pada DAS Bd. Katulampa

\begin{tabular}{ccc}
\hline No. & Nama Pos Hujan & Kewenangan \\
\hline 1 & Perkeb. Gn. Mas & BBWS Ciliwung Cisadane \\
\hline 2 & Rawa Gede & BBWS Ciliwung Cisadane \\
\hline 3 & Cilember & BBWS Ciliwung Cisadane \\
\hline 4 & Gunung Mas & BPSDA Ciliwung Cisadane \\
\hline 5 & Panjang & BPSDA Ciliwung Cisadane \\
\hline 6 & Pasir Muncang & BPSDA Ciliwung Cisadane \\
\hline 7 & Gadog & BBWS Ciliwung Cisadane \\
\hline 8 & Katulampa & BPSDA Ciliwung Cisadane \\
\hline 9 & Bojong Murni & BBWS Ciliwung Cisadane \\
\hline 10 & Naringgul & BMKG Bogor \\
\hline 11 & Bd. Katulampa & BMKG Pondok Bitung \\
\hline 12 & Gadog & BMKG Bogor \\
\hline 13 & Ciawi & BMKG Bogor \\
\hline
\end{tabular}




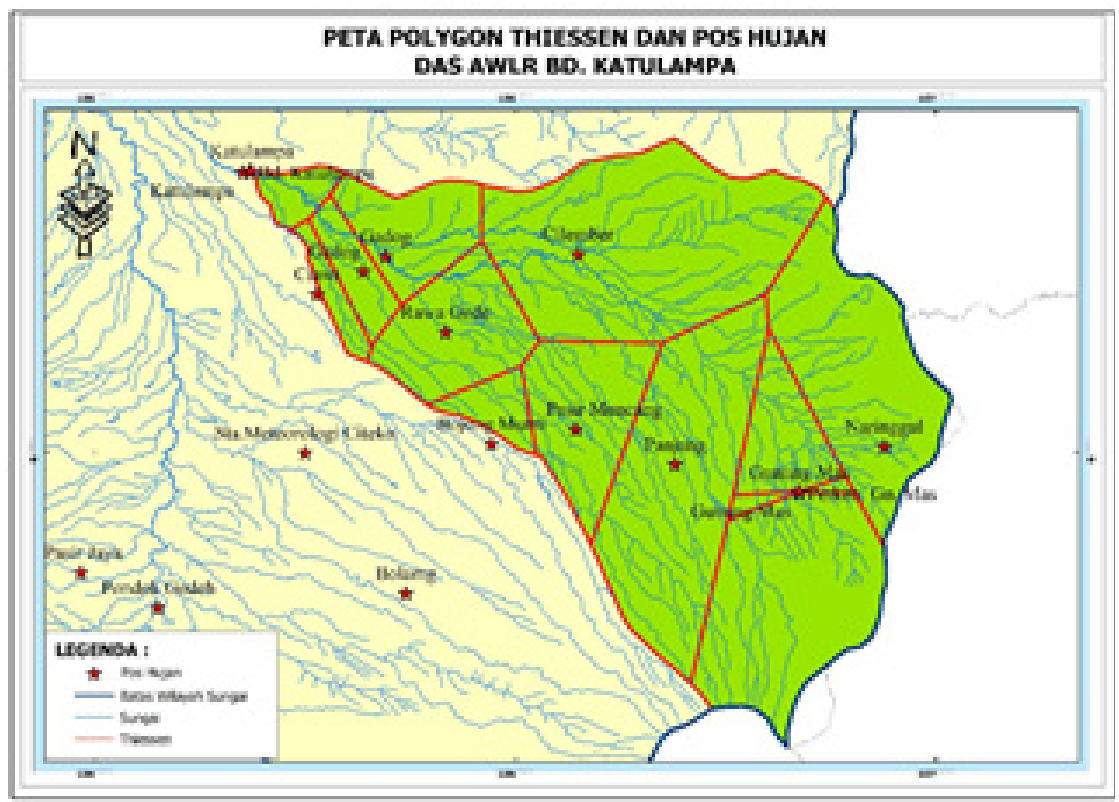

\section{Gambar 2. Sebaran Pos Hujan dan Polygon Thiessen Pada DAS Katulampa}

Berdasarkan hasil pengumpulan data, diketahui bahwa tidak semuanya pos hujan mempunyai data pencatatan hujan yang lengkap. Oleh karena itu, tidak semua pos hujan digunakan dalam analisis multi korelasi.

Analisis mutiple correlation memerlukan data dengan range series yang sama. Oleh karena itu diperlukan data curah hujan dan data debit dengan periode yang sama. , data yang akan dianalisis berupa data curah hu- jan dan data debit bulanan. Analisis memerlukan range data yang sama. Karena keterbatasan data, digunakan data pada rentang waktu tahun 2005. Adapun pos hujan yang mempunyai data lengkap pada tahun tersebut antara lain Perkeb. Gn. Mas (BBWS Cilcis), Gunung Mas (BPSDA Cilcis), Panjang (BPSDA Cilcis), Pasir Muncang (BPSDA Cilcis), dan Katulampa (BPSDA Cilcis).

Tabel 2. Data Curah Hujan dan Data Debit Bulanan

\begin{tabular}{|c|c|c|c|c|c|}
\hline Debit & & & Hujan & & \\
\hline Bd. Katulampa & Perkeb. Gn. Mas & Gunung Mas & Panjang & Pasir Muncang & Katulampa \\
\hline $\mathbf{Q}$ & $\mathbf{A}$ & B & $\mathrm{C}$ & $\bar{D}$ & $\mathbf{E}$ \\
\hline 2369.96 & 673 & 525.7 & 578 & 0 & 576.1 \\
\hline 2348.75 & 631 & 626 & 340 & 432 & 730 \\
\hline 2418.88 & 430 & 441 & 180 & 310 & 637 \\
\hline 1793.88 & 162 & 157 & 48 & 149 & 302 \\
\hline 1838.17 & 211 & 212 & 93 & 173 & 177 \\
\hline 1883.88 & 287 & 306 & 237 & 253 & 406 \\
\hline 1709.67 & 144 & 169 & 79 & 0 & 218 \\
\hline 1636.38 & 185 & 149 & 111 & 80 & 234 \\
\hline 1660.29 & 288 & 312 & 81 & 57 & 252 \\
\hline 1747.5 & 197 & 194 & 105 & 101 & 329 \\
\hline 1817.08 & 269 & 306 & 90 & 112 & 400 \\
\hline 1952.5 & 312 & 327 & 398 & 378 & 235 \\
\hline
\end{tabular}


Dari data hujan yang ada dilakukan analisis correlation dengan menggunakan bantuan program excell. Analisis yang pertama dilakukan dengan menggunakan single correlation untuk mengetahui korelasi masing-masing pos hujan. Hasil analisis single correlation ditampilkan pada Tabel 3 .

Tabel 3. Analisis Single Correlation

\begin{tabular}{cc}
\hline Pos Hujan & Single Correlation \\
\hline Perkeb. Gn. Mas & 0.887 \\
\hline Gunung Mas & 0.881 \\
\hline Panjang & 0.708 \\
\hline Pasir Muncang & 0.873 \\
\hline Katulampa & 0.886 \\
\hline
\end{tabular}

Analisis selanjutnya dilakukan dengan beberapa kombinasi untuk menguji masing-masing stasiun hujan. Kombinasi mulai dari 2 pos, 3 pos, 4 pos dan 5 pos. Dari masing-masing kombinasi, diambil nilai korelasi yang paling maksimum, kemudian dibuat grafiknya. Hasil analisis multiple correlation ditampilkan pada Tabel 4, sedangkan grafiknya ditampilkan pada Gambar 3.
Tabel 4. Hasil Analisis Multiple Correlation

\begin{tabular}{ccc}
\hline $\begin{array}{c}\text { Jumlah Sta- } \\
\text { siun }\end{array}$ & Korelasi & Kombinasi \\
\hline 2 & 0.86 & $\mathrm{CE}$ \\
\hline 3 & 0.87 & $\mathrm{CDE}$ \\
\hline 4 & 0.88 & $\mathrm{ACDE}$ \\
\hline 5 & 0.88 & $\mathrm{ABCDE}$ \\
\hline
\end{tabular}

\section{PEMBAHASAN}

Dari hasil analisa dengan single correlation, diketahui bahwa pos hujan dengan korelasi terbaik adalah pos hujan Perkeb. Gn. Mas. Dengan nilai korelasi 0.887. Sedangkan pos hujan dengan nilai korelasi terendah adalah pos hujan Panjang yaitu 0.708.

Hasil analisa dengan multi correlation menunjukkan bahwa pertambahan nilai korelasi bertambah dari kombinasi 2,3 dan 4 pos hujan. Akan tetapi pada kombinasi 5 pos hujan, pertambahan nilai korelasi tidak lagi signifikan. Hal ini menunjukkan bahwa penambahan pos hujan pada kombinasi 5 sebenarnya tidak diperlukan. Artinya pada DAS Bd. Katulampa, pencatatan pos hujan cukup terwakili dengan 4 pos hujan antara lain Pos Perkeb. Gn. Mas, Pos

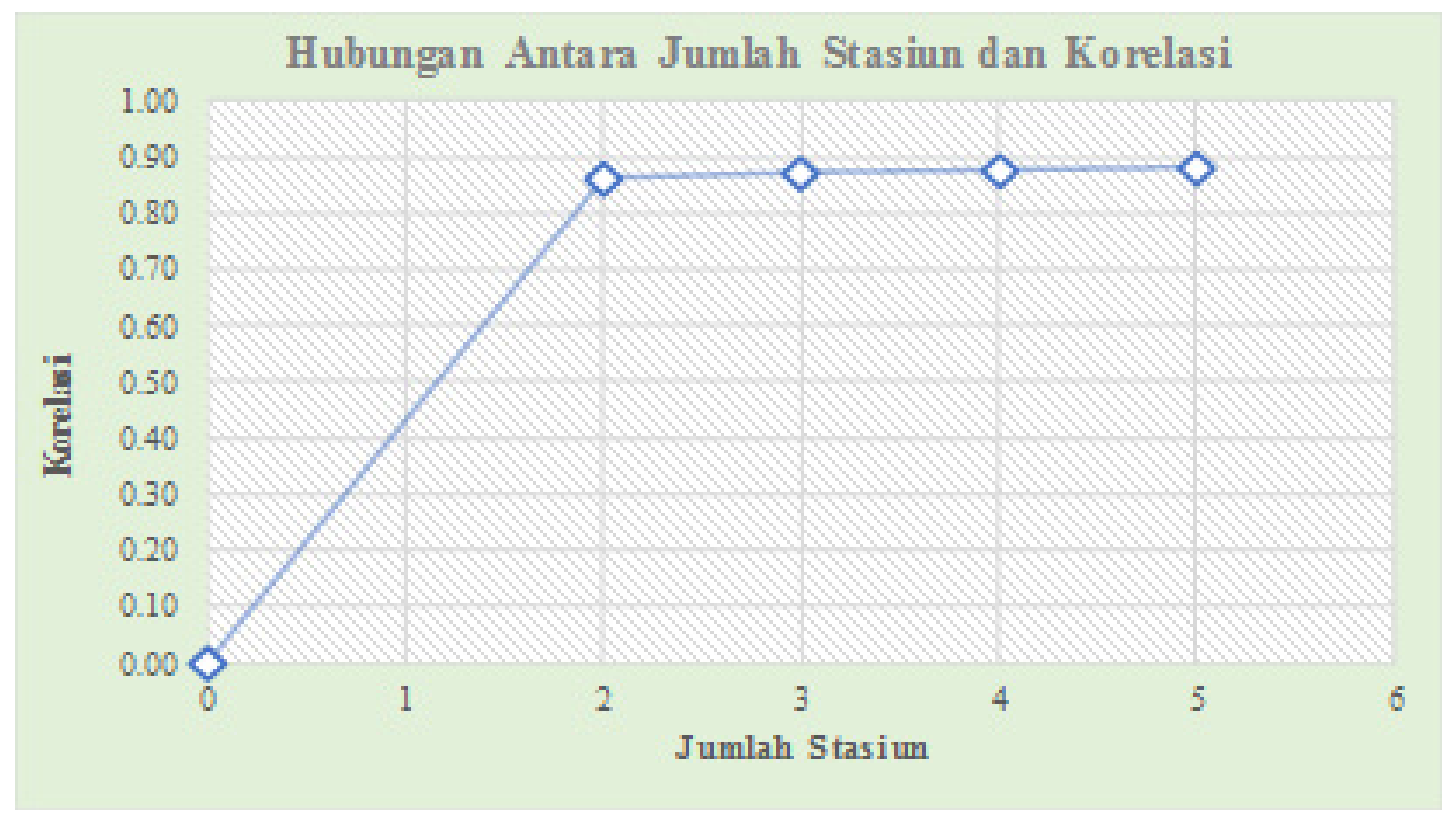

Gambar 3. Grafik Hubungan antara Jumlah Stasiun dan Nilai Korelasi 
Panjang, Pos Pasir Muncang dan Pos Katulampa.

Hasil dari analisis multi correlation dengan stepwise ini kemudian di cek dengan ketentuan yang dikeluarkan oleh WMO. Polygon thiessen yang dihasilkan 4 pos hujan hasil analisis, menghasilkan luas pengaruh pos hujan paling maksimum adalah $50.57 \mathrm{~km} 2$ yaitu Pos Pasir Muncang dan paling minimum $15.46 \mathrm{~km} 2$ Pos Katulampa. Dengan 4 pos hujan tersebut, luas pengaruh pos hujan masih masuk dalam ketentuan yang disyaratkan oleh WMO yaitu 575$5750 \mathrm{~km} 2$ untuk wilayah perbukitan. Adapun gambar polygon thiessen dengan 4 pos hujan dapat dilihat pada Gambar 3. Dari hasil ini perlu dipertimbangkan keberadaan pos-pos lain apakah akan tetap dioperasikan atau ditutup guna efisiensi biaya operasi dan pemeliharaan.

\section{SIMPULAN}

Analisis multi korelasi pada DAS Bd. Katulampa menghasilkan 4 (empat) pos hujan yang paling berpengaruh antara lain Pos Perkeb. Gn. Mas, Pos Panjang, Pos Pasir Muncang dan Pos Katulampa.

Polygon thiessen yang dihasilkan 4 pos hujan tersebut, menghasilkan luas pengaruh pos hujan paling maksimum adalah $50.57 \mathrm{~km} 2$ yaitu Pos Pasir Muncang dan paling minimum $15.46 \mathrm{~km} 2$ Pos Katulampa. Dengan 4 pos hujan tersebut, luas pengaruh pos hujan masih masuk dalam ketentuan yang disyaratkan oleh WMO yaitu $575-5750 \mathrm{~km} 2$ untuk wilayah perbukitan

\section{DAFTAR RUJUKAN}

Ayu, F., Shiami, R., \& Lasminto, U. (2019). Rationalization of Hydrology Station Net work Using Rainfall Ground and Satellite Data. 4(3), 225-229.

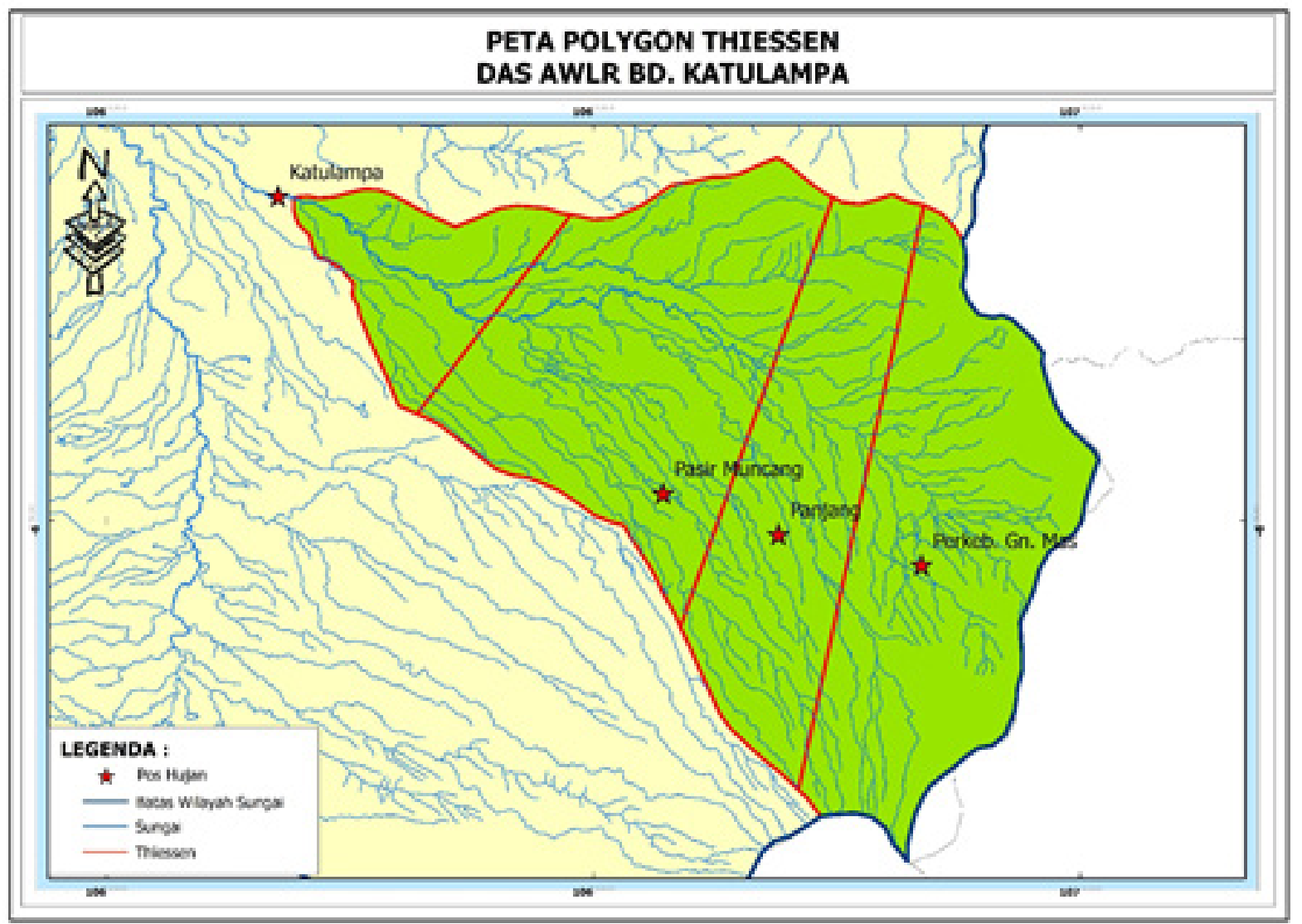

Gambar 3. Polygon Thiessen dengan 4 Pos Hujan Paling Berpengaruh 
Cipta, D. M., Suhartanto, E., \& Harisuseno, D. (2017). Evaluasi dan Rasionalisasi Ker apatan jaringan Pos Hujan dan Pos Duga Air dengan Metoda Stepwise di Sub DAS Brantas Hulu. Jurnal Mahasiswa Teknik Pengairan, 1(1), 1-9. https://doi.org/10. $11225 /$ jcss.22.426

G, Mirwan. R., Yuningsih, S. M., Fauzi, M., Desi, W., Asep, F., \& Lintang, G. (2019). Teknologi Kendali Mutu data Hidrologi Berbasis Skoring dalam Rangka Peningka tan Kualitas Data Hidrological Data Qual ity Control Technology Based on Scoring in The Framework of Data Quality Im provement. Prosiding Seminar Nasional Hari Air Dunia, 28-37.

Hadisusanto, N. (1978). Aplikasi Hidrologi. Malang: Jogja Mediautama.

Junaidi, R. (2015). Kajian Rasionalisasi Jar ingan Stasiun Hujan Pada Ws Parigi-Poso Sulawesi Tengah Dengan Metode Kagan Rodda Dan Kriging. Jurnal ilmu-ilmu teknik - sistem, 11(1), 22-31.

KemenPUPR. (2019). Prosedur Pelaksanaan Studi Rasionalisasi Jaringan Pos Hidrologi. Kurniawati, T., Suhartanto, E., \& Harisuseno, D. (n.d.). Evaluasi dan Rasionalisasi Ker apatan Jaringan Pos Hujan dan Pos Duga Air Dengan Metode Stepwise Di Sub DAS Lesti.

Rodda, K. (1972). Planning the spatial distri bution of hydrometeorological stations to meet an error criterion. In Casebook on Hydrological Network Design Practice (No. 324). WMO Publ.

WMO. (2008). Guide to Hydrological Prac tices, Hydrology - From Measurement to Hydrological Information.

Yuningsih, S. M., \& G, M. R. (2017). Pener apan Model Kendali Mutu Data Hidrologi Dalam Rangka Peningkatan Kualitas Data Implementation Oh Hydrology Data Qual ity Control Improvement. Jurnal Sumber Daya Air, 13, 131-146. 
8 JURNAL BANGUNAN, VOL. 25, NO.1, MARET 2020: 1-8 